\title{
Blood Pressure Responses in Isokinetic Dynamometry Test in Elderly Community Women: An Exploratory Study
}

\author{
Rubens Vinícius Letieri ${ }^{1,2 *}$, Guilherme Eustáquio Furtado ${ }^{3}$, Taís Rieping ${ }^{4}$, Mayrhon José \\ Abrantes Farias ${ }^{1}$, Ana Maria Miranda Botelho Teixeira ${ }^{3}$
}

\begin{abstract}
The aim of the study was to verify the systolic, diastolic and mean arterial pressure response in elderly women during isokinetic test. The study included 54 females (68.8 \pm 5.9 years) divided into two age groups (Group 1: 60 to 70 and group 2: above 71 years). BP was measured before and immediately after the isokinetic knee extension / flexion test in the concentric-concentric mode. After the test, significant elevations were observed in relation to the pre-test in SBP (G1: $\Delta \%=29.7 \%, \mathrm{G} 2: \Delta \%=20.6 \%, \mathrm{p}<.01$, respectively) and in MAP (G1: $\Delta \%=7.6 \%, \mathrm{G} 2: \Delta \%=8.4 \%, \mathrm{p}<.01$, respectively). The use of isokinetic tests produces elevations in systolic blood pressure and mean arterial pressure in elderly women. Increases occur independently of the age group studied. However, the increases detected do not appear to be of sufficient magnitude to constitute a health hazard whereby isokinetic tests can be safely applied in this population.

Keywords: muscle strength dynamometer, blood pressure, stress test.
\end{abstract}

\section{INTRODUCTION}

Muscle strength is one of the most important physical capacity, since it is fundamental for any movement. With the aging process, the body suffer many losses including the muscle strength capacity, which is related to sarcopenia and neuromuscular atrophy (Aagaard, Suetta, Caserotti, Magnusson, \& Kjær, 2010). The study of muscle strength has largely contributed to the prescription of physical exercise in elderly individuals, aiming to attenuate the losses of advancing age (Haraldstad et al., 2017; Walston, 2012). In addition, arterial hypertension also have been investigate in the aging field, because it has a high prevalence in the elderly population, generating a need for greater targeting of strategies to assist in the control of this variable in the elderly. The increase in blood pressure (BP) during the aging process is a contributor to the development of cardiovascular disease and hypertension (Da Cunha Nascimento et al., 2018).

The benefits of having an active life, doing exercise and avoiding the sedentarism is well known and recommended by important health organizations in the world (Chodzko-Zajko et al., 2009). Lately the recommendations not only focus in aerobic capacity but also to strength capacity (Peterson, Rhea, Sen, \& Gordon, 2010). Nowadays the combined exercise is the best option to preserve the functional capacity and prolong an independent life (Teixeira et al., 2016). Exercise plays an important role in the aid process in control of age-related disorders, however, to be able to assess whether the exercise was effective, it is necessary that individuals who undergo training programs do an assessment test of strength maximum muscle mass.

Some tests can be run to evaluate the strength capacity however, the gold test (Maximum muscular strength test) can be tricky for the

\footnotetext{
Manuscript received at June 26 ${ }^{\text {th }} 2018$; Accepted at November $27^{\text {th }} 2018$

${ }^{1}$ Physical Education Department, Federal University of Tocantins, UFT, Tocantins, Brazil

${ }^{2}$ Faculty of Sport Science and Physical Education, University of Coimbra, Coimbra, Portugal

${ }^{3}$ Research Unit for Sport and Physical Activity, CIDAF, Faculty of Sport Science and Physical Education, University of Coimbra, Coimbra, Portugal

${ }^{4}$ Laboratory of Sport and Exercise Psychology, Faculty of Sport Science and Physical Education, University Coimbra, Coimbra, Portugal

*Corresponding author: Email: rubens.letieri@gmail.com
} 
elderly population, once it is associate with increased BP during the test. The test is associate with physiological changes that can, in fact, influence the responses to exercise (Levinger et al., 2009), including the BP (Featherstone, Holly, \& Amsterdam, 1993). In the study by Blanchard et al. (2018), the authors hypothesized that individuals with high resting BP would exhibit lower rates of isokinetic muscle strength than individuals with normal BP. Contrary to the initial hypothesis, individuals with higher resting BP had higher values of muscular strength. BP responses during maximal muscle strength tests at different stages of aging need to be further clarified. We hypothesized that older women with more advanced ages may exhibit higher rates of $\mathrm{BP}$ and lower rates of muscle strength than those with the lower age range after isokinetic test.

Thus, to help clarify and reinforce the safety of isokinetic test application in this specific population the aim of the present study was to verify the acute response of BP in elderly women during the assessment of maximal muscle strength.

\section{Participants}

\section{METHOD}

The study is characterized as descriptive, transversal and quasi-experimental. The sample consisted of 54 females (68.58 \pm .09 years) participants in a university program of physical exercise. The subjects were categorized into two age groups, Group 1: 60 to 70 years old (65.45 \pm 2.62 years) And Group 2: above 71 years (74.14 \pm 3.07 years). The inclusion criteria were: a) age equal to or greater than 60 years; b) have no muscle-articular limitations in the involved segments; c) have medical release for participation. The exclusion criteria were: a) complete the test by voluntary / involuntary interruption; b) BP at rest above $140 \times 90 \mathrm{mmHg}$. Participants were given medical release for the practice and were advised to follow the usual medical advice regarding medications. All participants were informed about the methodological procedures and signed a Free and Clarified Consent Term (FCCT). The study respected the ethical procedures for research in humans (Res. 466/2012 of the National Health Council) and the Declaration of Helsinki. The protocol was approved by the Ethics and Research Committee of Unicatólica $\left(\mathrm{n}^{\circ}\right.$ 1175.175).

\section{Measures}

The evaluation of lower limb muscle strength was performed on a Biodex 3 System Pro $^{\circledR}$ Isokinetic Dynamometer (Biodex Biomedical Systems, Inc., Shirley, NY) and preliminary cycle ergometer heating (Monark Ergomedic 828). The maximum isokinetic torque $(\mathrm{Nm})$ was measured in the concentric-concentric mode at $60 \% \mathrm{~s}$ and three repetitions maximum extension/flexion of the knee dominant (Aquino Amorim \& Helm, 2006). Familiarization with the isokinetic test was performed in the week prior to the tests.

\section{Procedures}

The SBP and DBP were measured at rest and immediately after the test was performed using an automatic sphygmomanometer (Omron HEM $7113^{\circledR}$ ). During the resting measurement, participants were instructed to remain seated for a period of 3 to 5 minutes in a calm environment and were instructed not to talk during the measurement. Participants were instructed to stand with uncrossed legs, feet flat on the floor, backslid in the chair and relaxed; The arm was positioned at the level of the heart, supported, with the palm of the hand turned upwards and the clothes relaxed. The procedures for the measurement of Blood Pressure followed the recommendations of the $7^{\text {th }}$ Brazilian Guideline of Arterial Hypertension (Malachias et al., 2016).

\section{Statistical analysis}

A descriptive analysis of the data was performed (mean and standard deviation $( \pm)$ ). Normality was verified by the Shapiro-Wilk test and independent student $t$ tests for the Torque Peak and paired for the variables SBP, DBP and MBP. MBP was calculated using the formula: $M B P$ $=[(2 D B P)+S B P] / 3$. The percentage of change $(\Delta \%)$ was calculated using the formula: $\Delta \%=$ ((pos-pre) / pre) $* 100$. The level of significance was $95 \%(p<0.05)$. For all statistical analysis, 
Statistical Package for the Social Sciences version 23.0 was used (Armonk: NY, IBM Corporation).

\section{RESULTS}

Table 1

Mean values, standard deviation ( \pm ), and $\triangle \%$ of $S B P, D B P$ and $M B P$ before and after isokinetic test.

\begin{tabular}{lcccccc}
\hline & $60-70$ years $(\mathrm{n}=33)$ & \multicolumn{4}{c}{ Above 70 years $(\mathrm{n}=21)$} \\
\hline Variables & Pre & Post & $\Delta \%$ & Pre & Post & $\Delta \%$ \\
\hline SBP $(\mathrm{mmHg})$ & $112.9 \pm 9.6$ & $146.5 \pm 7.2^{* *}$ & $29.7 \%$ & $123.7 \pm 9.1$ & $149.3 \pm 7.1^{* *}$ & $20.6 \%$ \\
DBP $(\mathrm{mmHg})$ & $78.4 \pm 6.7$ & $77.1 \pm 4.3$ & $-1.6 \%$ & $79.9 \pm 6.7$ & $79.1 \pm 3.7$ & $-1.0 \%$ \\
MBP & $93.2 \pm 6.3$ & $100.3 \pm 4.2^{* *}$ & $7.6 \%$ & $94.5 \pm 6.3$ & $102.5 \pm 3.4^{* *}$ & $8.4 \%$ \\
\hline Note. ${ }^{* *}$ p $<0.01$ related to pretest; SBP $=$ Systolic Blood Pressure $(\mathrm{mmHg})$, DBP $=$ Diastolic Blood Pressure $(\mathrm{mmHg})$, \\
MBP = Medium Blood Pressure.
\end{tabular}

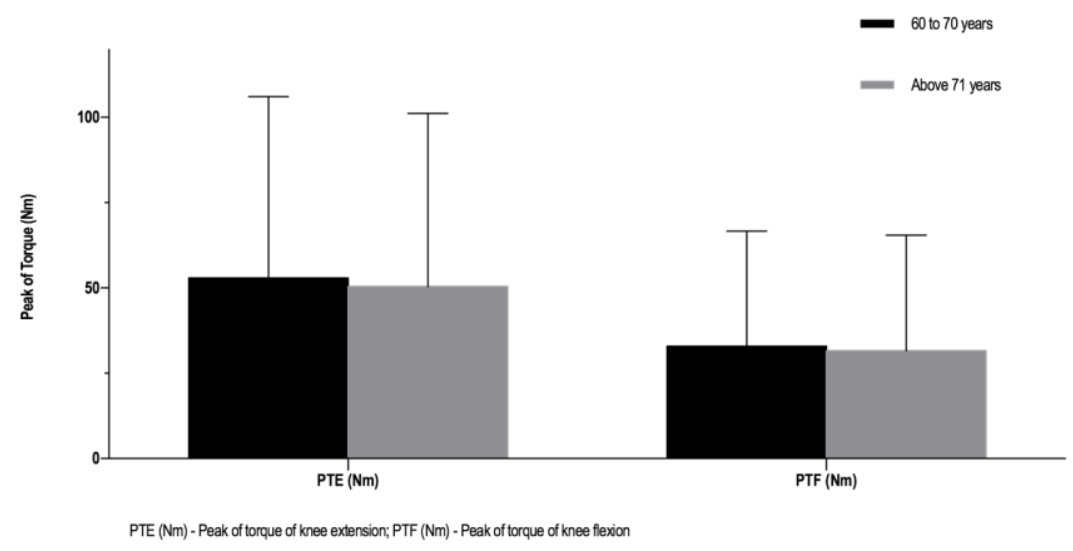

Figure 1. Peak of torque of Right and Left extension/flexion

\section{DISCUSSION}

In this paper, we describe BP responses to maximum isokinetic test in elderly women. This report is unique because it is a study that analyzes the BP at different stages of aging for maximum concentric effort in women of the community.

The responses in SBP, DBP and MBP observed in our study can be considered similar in both age groups. However, the mean values of MBP were significantly higher after the isokinetic test in the two age groups. It is possible that such elevation was influenced by increases in SBP. The observed increase in SBP in both groups can be explained by the type of muscle contraction used in the test.

Concentric contractions may induce elevated responses in cardiovascular variables when compared to eccentric contractions (Okamoto, Masuhara, \& Ikuta, 2006). Isokinetic contractions, when compared to isotonic and isometric contractions, may also present higher acute values in both SBP and DBP (Iellamo et al., 1997). Besides the type of contraction, the
The peak torque values $(\mathrm{Nm})$ showed no significant differences between the groups (EPT Group 1 vs. Group 2. $P=.357 ; 95 \%$ CI: -4.1 to 12.6; FPT. $P=.609 ; 95 \%$ CI: -3.5 to 6.06 , respectively). 
intensity of the effort and the progressive vasodilatation (decrease of the peripheral resistances). Thus, at this point, blood flow seems to have been sufficient to meet the metabolic needs of exercise (Carvalho, Marques, \& Mota, 2008).

The present study presents some limitations: the first is that the $\mathrm{BP}$ response was not controlled in the recovery period after exercise. The second is that the sample was composed only of women. Therefore, studies with different methodological designs are recommended.

\section{CONCLUSION}

The use of isokinetic tests produces elevations in systolic blood pressure and mean arterial pressure in elderly women. The increases occur independently of the studied age group, requiring a control for each applied test. However, the increases detected do not appear to be of sufficient magnitude to constitute a health hazard, so that isokinetic tests can be safely applied in this population.

\section{Acknowledgments:}

Nothing to declare.

\section{Conflict of interests:}

Nothing to declare.

\section{Funding:}

Nothing to declare.

\section{REFERENCES}

Aagaard, P., Suetta, C., Caserotti, P., Magnusson, S. P., \& Kjær, M. (2010). Role of the nervous system in sarcopenia and muscle atrophy with aging: Strength training as a countermeasure. Scandinavian Journal of Medicine and Science in Sports, 20(1), 49-64. https://doi.org/10.1111/j.16000838.2009.01084.x

Bakke, E. F., Hisdal, J., Kroese, A. J., Jørgensen, J. J., \& Stranden, E. (2007). Blood pressure response to isometric exercise in patients with peripheral atherosclerotic disease. Clinical Physiology and Functional Imaging, 27(2), 109-115. https://doi.org/10.1111/j.1475097X.2007.00720.x

Blanchard, A. R., Taylor, B. A., Thompson, P. D., Lepley, L. K., White, C. M., Corso, L. M., ... Pescatello, L. S. (2018). The influence of resting blood pressure on muscle strength in healthy adults. Blood Pressure Monitoring, 23(4), 185-190. https://doi.org/10.1097/MBP.00000000000003 25

Câmara, L. C., Ritti-Dias, R. M., Forjaz, C. L. de M., Greve, J. M., Santarém, J. M., Jacob-Filho, W., ... Wolosker, N. (2010). Respostas cardiovasculares durante avaliação muscular isocinética em claudicantes. Arquivos Brasileiros de Cardiologia, 95(5), 571-576. http://doi.org/10.1590/S0066782X2010005000147

Carvalho, J., Marques, E., \& Mota, J. (2008). Resposta hemodinâmica aguda a uma sessão de exercício físico multicomponente em idosos. Revista Portuguesa de Ciências Do Desporto, 8(1), 103$113 . \quad$ Retrieved from http://www.scielo.mec.pt/scielo.php?script=sci _arttext\&pid=S1645-

05232008000100011\&lng $=$ pt\&nrm $=$ iso\&tlng $=$ $\mathrm{pt}$

Chodzko-Zajko, W. J., Proctor, D. N., Fiatarone Singh, M. A., Minson, C. T., Nigg, C. R., Salem, G. J., \& Skinner, J. S. (2009). Exercise and physical activity for older adults. Medicine and Science in Sports and Exercise, 41(7), 1510-1530. https://doi.org/10.1249/MSS.0b013e3181a0c95 c

de Amorim Aquino, M., \& Leme, L. E. G. (2006). Isokinetic dynamometry in elderly women undergoing total knee arthroplasty: a comparative study. Clinics (Sao Paulo, Brazil), 61(3), 215-22. http://doi.org//S1807-59322006000300006

Featherstone, J. F., Holly, R. G., \& Amsterdam, E. A. (1993). Physiologic responses to weight lifting in coronary artery disease. The American Journal of Cardiology, 71(4), 287-92. Retrieved from http://www.ncbi.nlm.nih.gov/pubmed/8427169

Haraldstad, K., Rohde, G., Stea, T. H., Lohne-Seiler, H., Hetlelid, K., Paulsen, G., \& Berntsen, S. (2017). Changes in health-related quality of life in elderly men after 12 weeks of strength training. European Review of Aging and Physical Activity, 14(1), 8. http://doi.org/10.1186/s11556-0170177-3

Iellamo, F., Legramante, J. M., Raimondi, G., Castrucci, F., Damiani, C., Foti, C., ... Caruso, I. (1997). Effects of isokinetic, isotonic and isometric submaximal exercise on heart rate and blood pressure. European Journal of Applied Physiology, 75(2), 89-96. http://doi.org/10.1007/s004210050131

Levinger, I., Goodman, C., Hare, D. L., Jerums, G., Toia, D., \& Selig, S. (2009). The reliability of the 1RM strength test for untrained middle-aged individuals. Journal of Science and Medicine in Sport, 12(2), 310-6. http://doi.org/10.1016/j.jsams.2007.10.007

Malachias, M., Souza, W., Plavnik, F., Rodrigues, C., Brandão, A., Neves, M., ... Moreno Júnior, H. (2016). Capítulo 1 - Conceituação, Epidemiologia e Prevenção Primária. Arquivos Brasileiros de 
$\mathbf{5 6} \mid$ RV Letieri, GE Furtado, T Rieping, MJA Farias, AMB Teixeira

Cardiologia, $\quad 107(3), \quad 1-6$. http://doi.org/10.5935/abc.20160151

Okamoto, T., Masuhara, M., \& Ikuta, K. (2006). Cardiovascular responses induced during highintensity eccentric and concentric isokinetic muscle contraction in healthy young adults. Clinical Physiology and Functional Imaging, 26(1), 39-44. http://doi.org/10.1111/j.1475097X.2005.00651.x

Overend, T. J., Versteegh, T. H., Thompson, E., Birmingham, T. B., \& Vandervoort, A. A. (2000). Cardiovascular Stress Associated With Concentric and Eccentric Isokinetic Exercise in Young and Older Adults. The Journals of Gerontology Series A: Biological Sciences and Medical Sciences, 55(4), B177-B182. https://doi.org/10.1093/gerona/55.4.B177

Peterson, M. D., Rhea, M. R., Sen, A., \& Gordon, P. M. (2010). Resistance exercise for muscular strength in older adults: A meta-analysis. Ageing Research Reviews, $9(3)$, https://doi.org/10.1016/j.arr.2010.03.004

Symons, T. B., Vandervoort, A. A., Rice, C. L., Overend, T. J., \& Marsh, G. D. (2005). Effects of maximal isometric and isokinetic resistance training on strength and functional mobility in older adults. The Journals of Gerontology. Series A, Biological Sciences and Medical Sciences,
60(6), 777-781. Retrieved from http://www.ncbi.nlm.nih.gov/pubmed/1598318 2

Reichert, T., Kanitz, A. C., Delevatti, R. S., Bagatini, N. C., Barroso, B. M., \& Kruel, L. F. M. (2016). Continuous and interval training programs using deep water running improves functional fitness and blood pressure in the older adults. Age (Dordrecht, Netherlands), 38(1), 20. http://doi.org/10.1007/s11357-016-9882-5

Teixeira, A. M., Ferreira, J. P., Hogervorst, E., Braga, M. F., Bandelow, S., Rama, L., ... Pedrosa, F. M. (2016). Study Protocol on Hormonal Mediation of Exercise on Cognition, Stress and Immunity (PRO-HMECSI): Effects of Different Exercise Programmes in Institutionalized Elders. Frontiers in Public Health, 4, 133. https://doi.org/10.3389/fpubh.2016.00133

Vallejo, A. F., Schroeder, E. T., Zheng, L., Jensky, N. E., \& Sattler, F. R. (2006). Cardiopulmonary responses to eccentric and concentric resistance exercise in older adults. Age and Ageing, 35(3), 291-297. https://doi.org/10.1093/ageing/afj082

Walston, J. D. (2012). Sarcopenia in older adults. Current Opinion in Rheumatology, 24(6), 623627.

http://doi.org/10.1097/BOR.0b013e328358d59 b

All content of Journal Motricidade is licensed under Creative Commons, except when otherwise specified and in content retrieved from other bibliographic sources. 